\title{
THE EFFECT OF CRUDE OIL PRICES FLUCTUATIONS ON THE AGRICULTURAL PRODUCERS`PERFORMANCE EFFICIENCY
}

\author{
Biljana Ivanova ${ }^{1}$, Ilija Ivanov ${ }^{2}$, Ljiljana Dimitrijević ${ }^{3}$ \\ *Corresponding authorE-mail: lolabgdyu@hotmail.com
}

\begin{abstract}
A R T I C LE IN F O
A B S T R A C T

Review Article

Received: 19 June 2018

Accepted: 14 August 2018

doi:10.5937/ekoPolj1803147I

UDC [338+665.613/.617]:[631:346.232]

Purpose. The development of agriculture and the security of food supply primarily on the domestic market represent the base of the economic development, and of economic and social stability of a country. Methodology. By using the VaR method, which is the best available risk-measuring technique, the crude oil price fluctuations will be followed in a designated period, in order to understand its influence on

Keywords:

crude oil, prices, agricultural producers, VaR method.

JEL: Q14, Q17. the creation of the business policy of agricultural producers. Results. A significant support for the development of agriculture is provided by the leading companies in the crude oil and oil derivatives industry. Conclusions. The aim of the current study is to comprehend the level of influence of crude oil prices as a global economic factor on the behavior of agricultural producers.
\end{abstract}

(C) 2018 EA. All rights reserved.

\section{Introduction}

Agriculture is a strategic area of the economy, and the entire social development is based on it. Having this in mind, the supportive measures for further development of the agricultural market must have a national frame, with participation of relevant producers who can contribute to the economic strengthening of the agribusiness production.

With the rise in prices of agricultural produce, as a dominating trend in the past several decades (Grunert, 2005; Bellemare, 2014), the economy and social costs increase as well. This process can have an effect on consumers' health, education, family ties and the standard of living. If the prices of agricultural products (Du et al., 2011; Kilian, Murphy, 2014) are observed over a longer period of time, it is noticeable that the changes are non-linear, i.e. they are under the influence of global economic cycles and the demand for these products in countries with high population numbers (IMF, 2016). Particularly relevant research in the field of price fluctuation of agricultural goods

1 Biljana Ivanova, M.A., Military Academy, University of Defence, Pavla Jurišića Šturma br. 33, 11000 Belgrade, Serbia, 065/3130328, lolabgdyu@hotmail.com, 0000-0002-4722-770X.

2 Ilija Ivanov, Singidunum University, Danijelova 32, 11000 Belgrade, Serbia, 064/3021951, marko.bojic2014@gmail.com,0000-0001-5936-4085

3 Ljiljana Dimitrijević, PhD, Faculty of Business Economics and Entrepreneurship, Mitropolita Petra br. 8, 11000 Belgrade, Serbia, +381 641388 474; E-mail: ljsrecka3014@gmail.com 
and the creation of policy by the agricultural producers are related to raw materials used in production. Among multiple factors, the crude oil price fluctuation, as a global economic factor (Mensi et al., 2017; Ignjatijević, Čavlin, 2017), significantly affects the business policy of agricultural producers. Support for agribusiness is welcome in any form, especially in the period of intense field work. Preparation requires the use of adequate equipment. An important part of the budget are the costs of maintenance of agricultural machinery. This includes fuel costs. Rise in the crude oil prices leads to the rise in costs of basic production input, such as fertilizer, which in return leads to higher costs of production of agricultural products. This then leads to the change in business policy of agricultural producers.

In relations to this, creators of the agricultural policy, as well as traders of agricultural goods (Nazlioglu et al., 2013), may find use in methods for risk identification and management in the crude oil sector. The events in the global assets and financial market(Vučković et al., 2017) have forced the global regulatory institutions to begin developing minimal standards for risk management for financial and non financial institutions. Risk management is in essence focused on humans - their way of thinking, whereas information solutions are tools for risk management. Using the VaR method, as the most suitable one for risk measuring (The Basel Committee took it as such, as well), but also with the development of an internal method for market risk (Dinică, Bale, 2014) measuring based on the VaR method, it is possible to create a risk management image in trade. In other words, it is possible to find answers to the question if a company can create adequate earnings, is it efficiently utilizing available tools, can it fulfill its obligations on time etc.

Subjects interested in these answers may be creditors, investors, shareholders, other companies but also individuals who find themselves in the position of stakeholders.

\section{Materials and methods}

Risk is an essential element of human activities. Risk entails a situation in the future with multiple alternative solutions and a certain realization possibility. In other words, in the given situation there is unpredictability about the outcomes and the probability that the outcome is unfavorable (loss possibility). It cannot be eliminated, but it can be controlled and to a certain degree managed through risk management. Risk can also be defined as: a possibility of a loss, a probability of a loss, uncertainty, a discrepancy of real from expected results or a probability of any outcome other than the expected one. The common elements for the multiple definitions are uncertainty and loss.

According to (Barjaktarović, 2013; Barjaktarović, Jeremić, 2013), the methods for market risk assessment are divided into traditional ones and the modern ones. The traditional methods start from the premise that the value of instruments is equal to the current value of future monetary flows which comprise the instrument. The assumption is that the future equals the present, in other words - it is predictable. It is suitable for a smaller number of instruments in the portfolio. The modern methods include 
sensitivity analysis, extreme events testing, scenario testing, CAPM and VaR methods. Their common traits are portfolio creation within market uncertainties. They take into account multiple parameters: yield, taken risk, diversification effect and mutual dependency of financial instruments in the portfolio.

Cvetinović (2008) says that an adequate approach is to start defining a risk management strategy, and then analyze which software solutions should be included in the risk management process. Software solutions can be used for different calculations, transactions measurements, interest rate calculation, volatility and correlation, inclusion of control modules for risk control in every application used by the business entity, not just in the risk management application.

Barjaktarović (2013) states that the development of the financial sector brings about many news in the field of risk management, and especially in the field of modelling of market, credit and operational risk. The main methodology for risk management is the Value-at-Risk (VaR) method, which is used in combination with other techniques for business risk minimizing, in order to achieve optimal business results.

It is believed that the Var method is currently the best available method for risk management. Three basic methods of VaR are: the analytical or parametric, the historical, and the Monte Carlo method. Each of them has its own merits and pitfalls, and the right one needs to be selected for any given problem.

The historic simulation belongs to the group of non-parametric VaR calculation methods. What all non-parametric methods have in common is that they use empirical divisions extracted from the observed data. On the other hand, the parametric approach entails assumptions about the theoretical yield divisions. In sum, in the parametric methods there is the assumption about the division of the portfolio's yield, whereas in nonparametric methods, the division is established empirically. The basic assumption in this method is that the near future will be very similar to the recent past, and that based on the data from the recent past, the risks of the near future can be evaluated. There are several ways in which the VaR can be calculated using the method of historical simulation. Some of the methods of the historical simulations are, for instance, the standard model of historical simulation, the simulation model weight by time (BRW model), the Hull-White model of historical simulation (where the GARCH and EWMA methods are used to test volatility) etc. Weighed models have been developed in the recent years with the standard methodology and they greatly improve the standard approach and remove the majority of flaws from the historic simulation (Dowd, 2006).

The first step of historical simulation is to identify the instruments in the portfolio and to collect the data about the time series for these instruments in a given past time period. It is necessary to collect enough historical data for the observed instruments. After that, the yield percentages are calculated on the portfolio during a certain time period in the past (it can be a day, a week, a month etc.), according to the given formula (Dowd, 2006): 


$$
r=\frac{p_{1}-p_{0}}{p_{0}}
$$

With:

$p_{0}-p_{1}$ - price at the onset of the observation period,

$p_{1}-p_{0}$ - price at the end of the observation period.

In the second step, the parts of the portfolio for which we wish to calculate the yield are used, so as to simulate the hypothetical yield (for the future time period). This hypothetical yield could be realized under the assumption that the portfolio was held in the time of observation. The third step is the formation of histograms for the simulated portfolio yields. The fourth step is reading the VaR from the histogram of yields, as the given quantile.

The historical simulation has some clear advantages due to its simplicity. It does not make any assumptions about the statistical division, not does it require evaluations of volatility and correlation. All that is needed is the time series of the portfolio yield.

A problem with the historical method is that the results of the historical simulation are completely dependent on the measured results in the given time period (Damnjanović et al., 2017). Therefore, a serious flaw of the historical simulation method is that it assumes that the history will repeat itself. There is a possibility that the price change scenario, which would otherwise cause a significant loss, was not noted in the price history which were used in the historic simulation for VaR calculation.

\section{Results}

The four basic steps for calculating the VaR value for the crude oil price fluctuations are:

- Determining the time frame (time horizon) for which the risk evaluation (i.e. possible loss) is being calculated; usually for a single day, ten days, a month, and for one year the longest. In this case, the time periods taken are 50,250 and 365 days.

- Choosing the confidence interval for which the VaR evaluation is being evaluated, most-commonly $95 \%$ and $99 \%$, which was the case in the current analysis as well.

- Adoption of the model for the distribution of probability for the change outcomes for the means or for the portfolio based on the data from the recent past and the broadness of the time window of this data.

- VaR estimate calculation based on the previously adopted criteria and the accuracy control of the VaR mode with the so-called back testing.

In case of a portfolio with multiple assets, the general formula for the calculation of the portfolio value is (Cvetinović, 2008):

$$
V=\sum_{i} f\left(\beta_{i}, \alpha_{i}\right)
$$


where:

$V$ - portfolio value change,

$f\left(\beta_{i}, \alpha_{i}\right)$ - function determining the value of the portfolio component, $\alpha_{i}$ - sensitivity of the portfolio component to the risk factor and

$\delta_{i} \quad \beta_{i}$ - percent of price change in the risk factor

Figure 1. Raw crude oil price in the time period 01.01.2008 - 01.01.2018

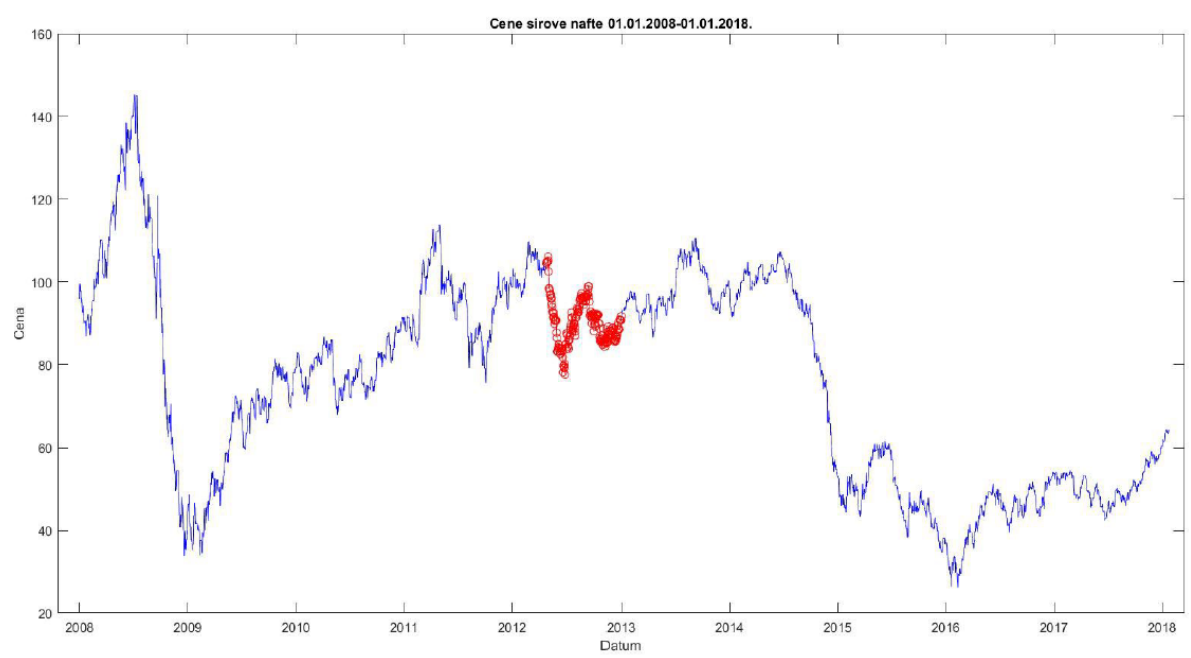

Source: Authors' calculations

Figure 2. Raw crude oil price in the period 26.04.2012 - 31.12.2012.

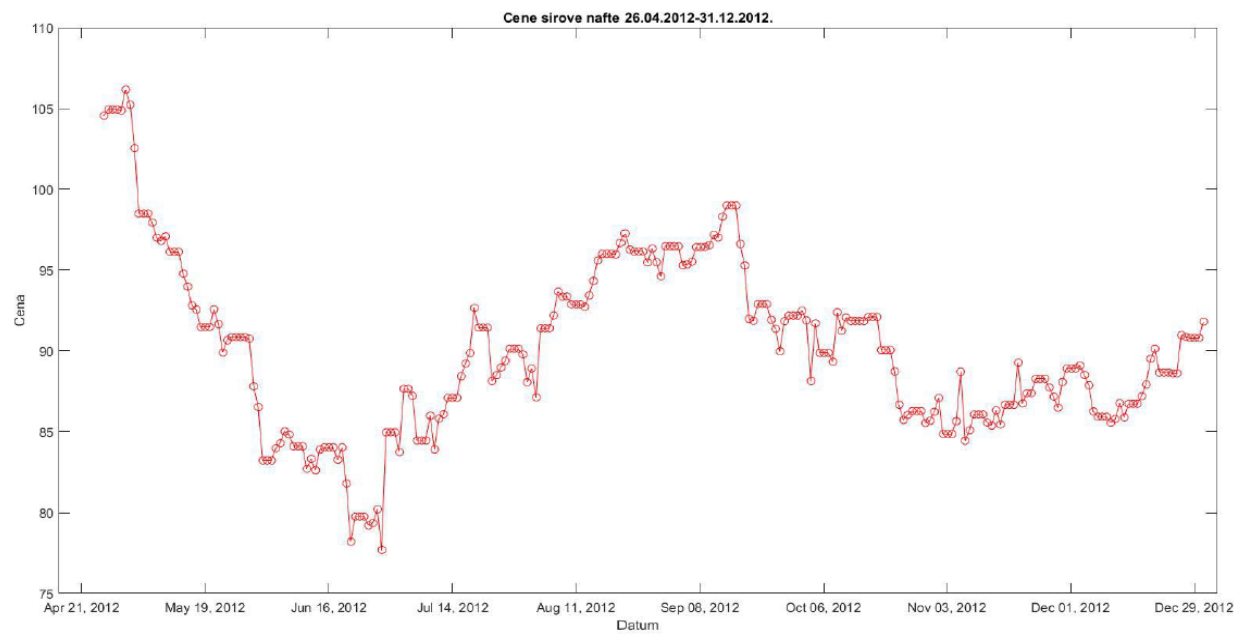

Source: Authors' calculations 
If the model of historical simulation (The basic Historical Simulation model - BHS) is adopted as the model for the distribution of the probability for the outcomes of change, the method of VaR calculation basically boils down to the analysis of the histogram representing the change in value means. In the Figure 1 the raw oil prices change for the period 01.01.2008 - 01.01.2018 is given(available at: www.macrotrends.net) What is particularly highlighted is the period 28.04.2012-31.12.2012, as an example of the time window containing 250 data points which are used for VaR calculations on the day of 01.01.2013. These 250 data points are separately shown in Figure 2, and the adequate changes for the same time period on the Figure 3.

Figure 3. Raw crude oil price in the period 26.04.2012 - 31.12.2012.

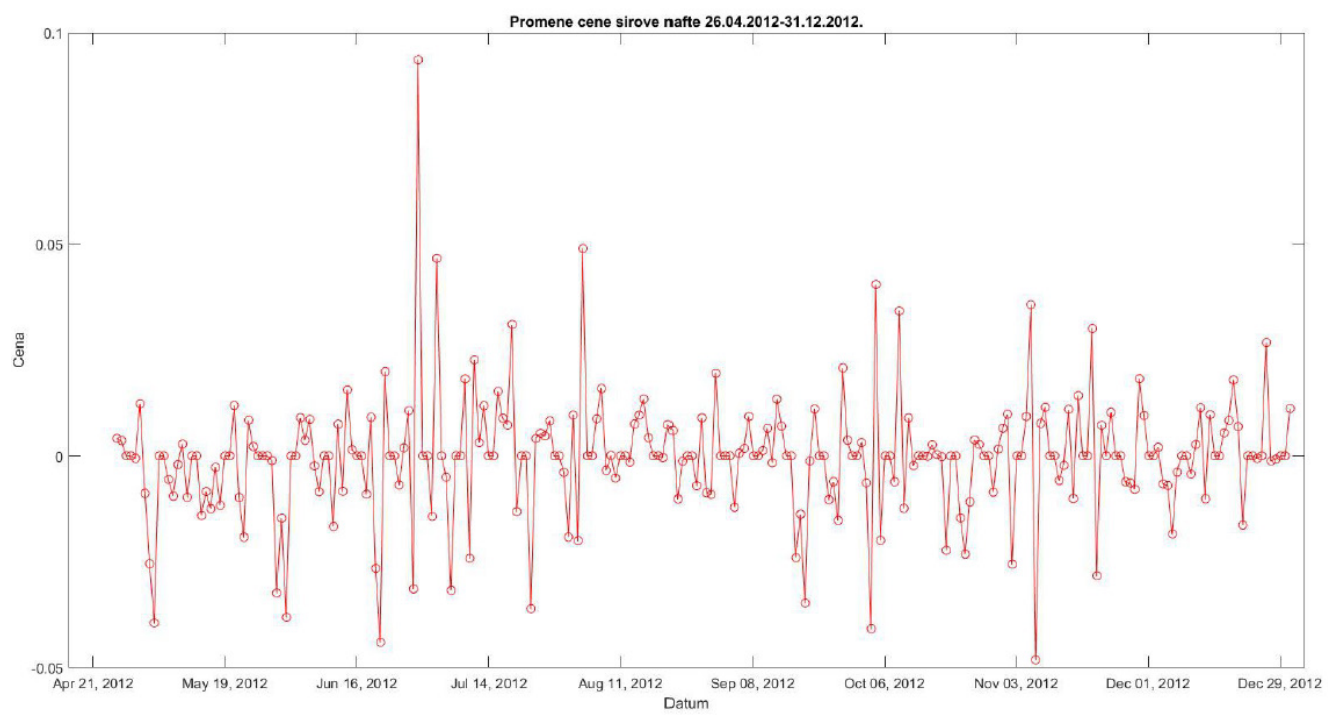

Source: Authors' calculations

The histogram of crude oil price change from the Figure 3 is given in the Figure 4, with particularly marked vertical lines denoting the borders to the right of which the $95 \%$ and $99 \%$ variability is. The values on the horizontal line which respond to these borders represent the evaluation of the volatility change of prices with the confidence interval of $95 \%$ and $99 \%$. 
Figure 4. Histogram of raw crude oil price fluctuation in the period 26.04.2012 - 31.12.2012.

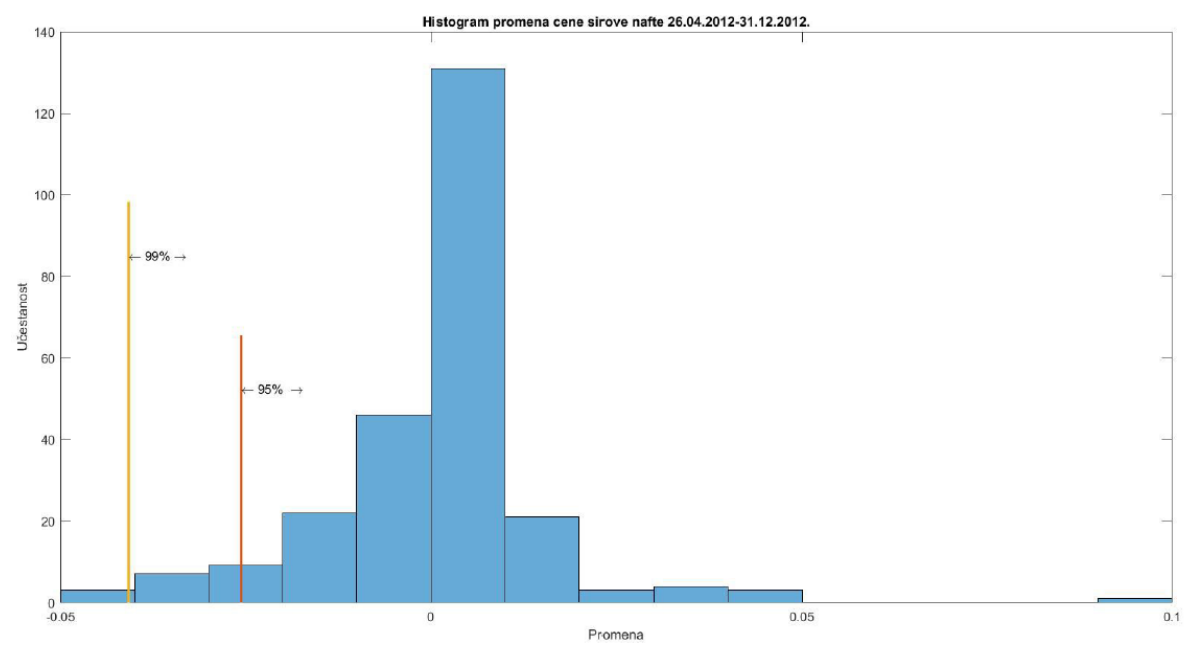

Source: Authors' calculations

Figure 5. VaR of crude oil prices for the period 01.01.2013-01.01.2018 - estimation window of 50 days

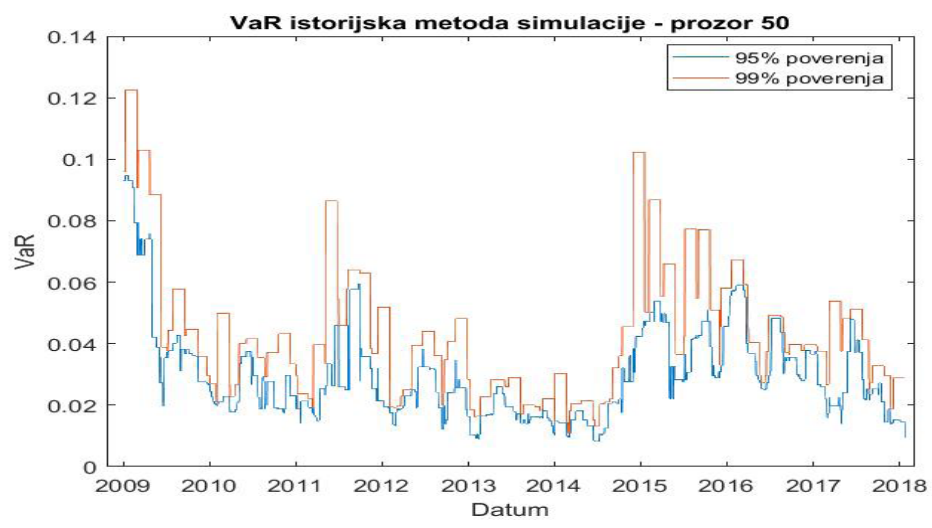

Source: Authors' calculations

Figure 5, 6 and 7 present the estimated VaR values of the raw crude oil prices for the period 01.01.2013 - 01.01.2018 with the estimation windows of 50, 250 and 365 days, respectively. In all three windows, the VaR value can immediately be noted for the confidence intervals of $99 \%$ and the $95 \%$, which was expected. Besides that, it can be noted that the longer the estimation window is, the smaller the daily fluctuation peaks of VaR are. In other words, the VaR value figure becomes smoother. This means that due to stronger influence of more data points from the past, the daily changes noted directly before the day of change have less effect in percentages on the calculated value when the window is larger. 
Figure 6. VaR of crude oil prices for the period 01.01.2013-01.01.2018 - estimation window is 250 days

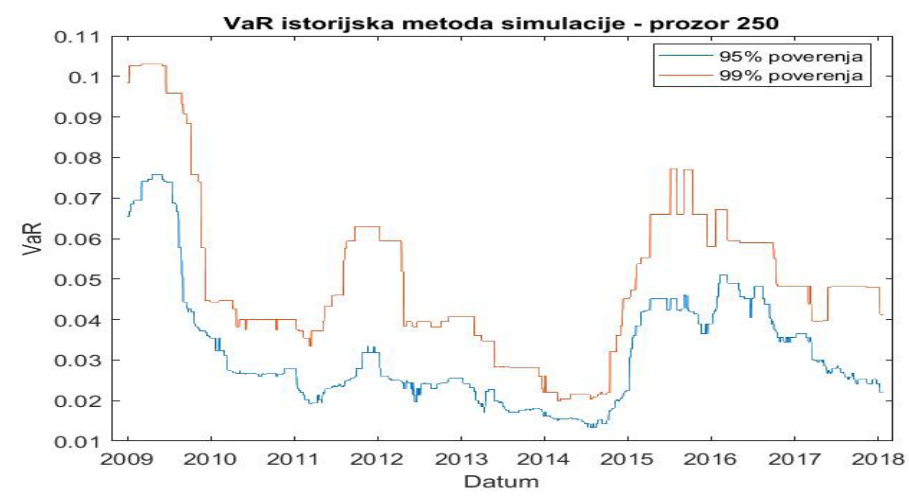

Source: Authors' calculations

Figure 7. VaR of crude oil prices for the period 01.01.2013 - 01.01.2018 - estimation window 365 days

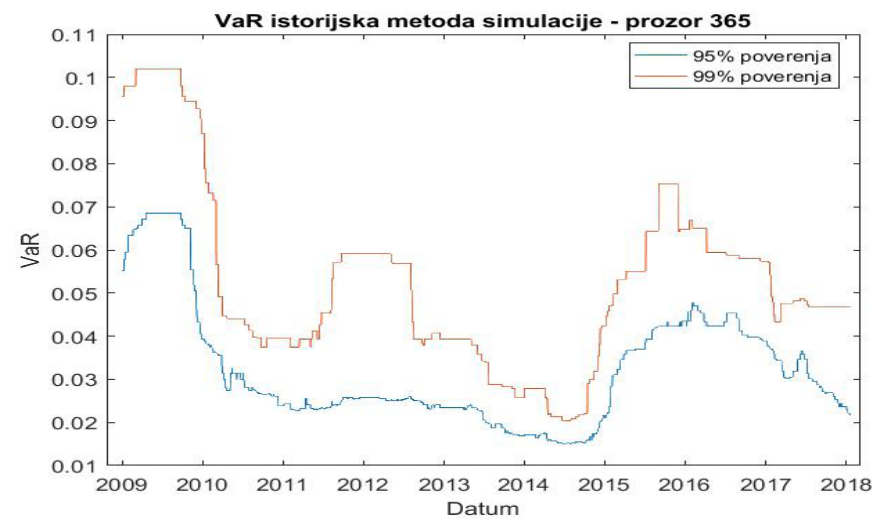

Source: Authors' calculations

The described procedure is used for VaR calculation, i.e. for volatility calculation in the time period (time horizon) of one day. If an estimate for a longer period of time is needed ( $\mathrm{n}$ days) in case of a historical simulation, there is no practically simple way for the single-day VaR to be recalculated for a longer period of time (Cvetinović, 2008). If a parametric method is used, the following formula can be utilized:

$$
V o l_{n \text { dana }}=\sqrt{n} V o l_{1 \text { dan }}
$$

So far, there has not been a simple theoretical method to take VaR which was originally calculated using the historical simulation, for one time period and transform it into VaR for another time period, as is possible with the parametric method (Cvetinović, 2008). 


\section{Discussions}

The data analyzed in the model refer to the period 2002 - 2017. the main reason why the crude oil price change was analyzed in the given time frame are the two key global financial events, which affected the crude oil price change and the price of agricultural production: the financial crisis after 2008 and the crude oil crisis of 2014. Based on that, it was logical to observe this period, having in mind the interdependency between the crude oil price, as one of the key raw materials in the agricultural production, and the behavior of agricultural producers.

Plenty of research in the fluctuation of crude oil prices and the prices of agricultural products in a given time period (Shahzad et al., 2018) show that the change in the price of agricultural products followed the change of crude oil prices. During the world economic crisis 2008-2009 a large rise in the price of agricultural products was followed by a large rise in the crude oil price. This shows a great level of correlation(Chatrath et al., 2014). World crude oil market experts explain the fall in crude oil prices in 2014 as a consequence of recession in Europe, the slowed growth in China, return to the global leadership position in domestic production and the stable crude oil reserves in the US, normalization of crude oil production and export in Libya and the inability of Saudi Arabia to decrease its share in the raw crude oil supply to the world within OPEC, since the price of $\$ 100$ per barrel suited their needs(Ji et al., 2014), and slightly lower prices were less damaging to them than to their competitors. This situation caused the decreased crude oil prices to lead to lower prices of crude oil derivatives, and through that lower calculative production price.

Based on the analysis ran using the VaR method, the agricultural products can form a certain image and expectations regarding the future change in crude oil prices, and therefore raw material prices.

\section{Conclusions}

Due to large crises which appear and the raw crude oil price oscillations in the global market, the production costs of agricultural products are rising. The fulfilled results in the agro-sector can affect the foreign trade balance, but also the entire national economy. In order for a company to run successfully, and to make adequate decisions at the right time, it is necessary to continually analyze and manage the risks in the agro-industry. The achieved results in the agro-sector can affect the improvement of the foreign trade balance and the balance of the entire national economy. To survive in the market, it is necessary to continuously follow the political situation and possible wars, as well as properly manage the limited resources.

The historical model of VaR, as well as many other models, does not have the perfect presentation of value for risk minimizing. A problem with the historical method is that the results of the historical simulation completely depend on the data created at a given point in time. On the other hand, the historical VaR method represents a quick and easy way to provide an estimate of future value with a lot of precision. 
The VaR model is a good base which can provide us with expected value of the confidence interval from $95 \%$ to $99 \%$ (Tong et al., 2013). This shows that the use of the historical VaR model for the estimate is a good base for making future decisions of companies. For a more precise estimate and to overcome the flaws of the historical VaR method - which expects that the history will repeat itself, without having a historic record of a similar scenario - it is necessary to use multiple models for the estimation of future models in order to get the optimal result. Because of all of this, a single approach is not enough for risk management on the market, since the results of the analyzed method are far from perfect. However, in synergy with other relevant factors, it represents a good starting point for estimation.

\section{Conflict of interests}

The authors declare no conflict of interest.

\section{References}

1. Barjaktarović L. (2013). Risk Management, Singidunum University, Belgrade

2. Barjaktarević, L., Jeremić, Lj. (2013). Financial Crisis and Risk Management of Insurance and Banking. Economic Institute, Belgrade.

3. Bellemare, M.F. (2014). Rising food prices, food price volatility, and social unrest. American Journal of Agricultural Economics, 97 (1), 1-21.

4. Chatrath, A., Miao, H., Ramchander, S. (2014). Crude oil moments and PNG stock returns. Energy Economics, 44(7), 222-235.

5. Cvetinović M. (2008). Managing risks in financial operations, Singidunum University, Belgrade.

6. Damnjanović, R., Ivanov, N., Milenković, N. (2017). Mathematical modeling of the price of action. ODITOR, Centar za ekonomska i finansijska istraživanja, 3(3), 13-33.

7. Dinică, M.C., Bale, E.C. (2014). International Crude oil Futures and Romanian Oil Companies: Volatility, Correlations and Causality. Procedia Economics and Finance, 15(4), 1396-1403.

8. Dowd, K. (2006). Retrospective Assessment of Value-at-Risk. RiskManagement: A Modern Perspective. San Diego, Elsevier.

9. Du, X., Cindy, L.Y., Hayes, D.J. (2011). Speculation and volatility spillover in the crude oil and agricultural commodity markets: a Bayesian analysis. Energy Economics, 33(3), 497-503.

10. Grunert, K.G. (2005). Food quality and safety: consumer perception and demand. Eur. Rev. Agric. Econ, 32 (3), 369-391.

11. Ji, Q., Geng, J.B., Fan, Y. (2014). Separated influence of crude oil prices on regional natural gas import prices. Energy Policy, 70(7), 96-105. 
12. Ignjatijević, S., Čavlin, M. (2017). Analysis of causes and consequences of corruption in the company. ODITOR, Centar za ekonomska i finansijska istraživanja, 3(3), 35-59.

13. IMF. (2016). Commodity market developments and forecasts, with a focus on special feature title: special feature head the energy transition in an era of low fossil fuel prices. World Econ. Outlook 2-14.

14. Kilian, L., Murphy, D.P. (2014). The role of inventories and speculative trading in the global market for crude oil. Journal of Applied Economics, 29 (3), 454-478.

15. Macrotrends, http://www.macrotrends.net/21. february 2018.

16. Mensi, W., Hammoudeh, S., Shahzad, S.J.H., Shahbaz, M. (2017). Modeling systemic risk and dependence structure between oil and stock markets using a variational mode decomposition-based copula method. Journal of Banking and Finance, 75(2), 258-279.

17. Nazlioglu, S., Erdem, C., Soytas, U. (2013). Volatility spillover between oil and agricultural commodity markets. Energy Economics, 36(5), 658-665.

18. Shahzad,S.JH., Hernandez, J.A., Al-Yahyaee, K.H., Jammazi, R. (2018). Asymmetric risk spillovers between oil and agricultural commodities, Energy Policy, 118(3), 182-198

19. Tong, B., Wu, C., Zhou, C. (2013). Modeling the co-movements between crude oil and refined petroleum markets. Energy Economics, 40(2), 882-897.

20. Vučković, B., Veselinović, B., Drobnjaković, M. (2017). Financing of permanent working capital in agriculture. Economics of Agriculture, 64(3), 1065-1080. 